\title{
DERMEVAL SAVIANI E SUA "HISTÓRIA DAS IDEIAS PEDAGÓGICAS NO BRASIL": EM BUSCA DA COMPREENSÃO DE UM AUTOR E DE UMA OBRA
}

\author{
Joseane de Fátima Machado Silva
}

\section{RESUMO}

O presente texto pretende compreender a escrita da obra Histórias das ideias pedagógicas no Brasil através da análise dos aspectos intratextuais, extratextuais e intertextuais percebidos na conjuntura histórica da vida do autor e de produção da obra.Nesse sentido, o texto aborda a vida de Dermeval Saviani: a família, a infância e os estudos;a vida profissional e acadêmica: atividades profissionais, produções e publicações;a obra História das Ideias Pedagógicas no Brasil: a compreensão de uma produção intelectual; e conclui com os apontamentos finais. A intenção da análise não é recontar a obra, tampouco julgar se as ideias do autor estão adequadas ou inadequadas, mas ir além, compreender as razões de tais ideias, suas estratégias teóricas e metodológicas, assim também como os discursos que utilizou no intento de alcançar os seus objetivos.

Palavras-chave: Dermeval Saviani; História das ideias pedagógicas; História da Educação.

\section{DERMEVAL SAVIANI AND HIS "HISTORY OF PEDAGOGICAL IDEAS IN BRAZIL": IN SEARCH OF UNDERSTANDING AN AUTHOR AND A WORK}

\begin{abstract}
The present paper aims to understand the writing of the work History of Pedagogical Ideas in Brazil through the analysis of intratextual, extratextual and intertextual aspects observed in the historical context of the life of the author and of production of the work. In this sense, the text approaches the life of Dermeval Saviani: family, childhood and studies; academic and professional life: professional activities, productions and publications; the work History of Pedagogical Ideas in Brazil: understanding an intellectual production; concluding with the final notes. The analysis is not intended to tell the work nor determinate whether the ideas of the author are appropriate or inappropriate, but to go further, understanding the reasons for such ideas, their methodological and theoretical strategies, and the speeches used in order to achieve their objectives.
\end{abstract}

Keywords: Dermeval Saviani; History of Pedagogical Ideas; History of Education.

\section{Introdução}

Para compreender a escrita da obra "História das ideias pedagógicas no Brasil" é indispensável considerar os aspectosintratextuais, extratextuais e intertextuais percebidos na conjuntura histórica da vida do autor e de produção da obra. Nesse sentido,esse texto se ampara na hipótese de que uma obra pode ser resultado das escolhas teórico-metodológicas do autor queenvolve um determinado discurso que, por conseguinte não podem ser afastadas da sua história de vida pessoal e acadêmica.

Diante disso, este texto está ancorado em duas das proposições de Bloch (2001) ${ }^{1}$, a primeira se refere à palavra que deve dominar e iluminar um estudo: compreender; a segunda considera que tudo, as causas em história como em outros domínios, não são 
postuladas, são buscadas. Portanto, busca-se aqui compreender a obra "História das ideias pedagógicas no Brasil" através da análise do contexto de vida de seu autor.

Para tanto, o texto aborda a vida de Dermeval Saviani: a família, a infância e os estudos;a vida profissional e acadêmica: atividades profissionais, produções e publicações;a obra História das Ideias Pedagógicas no Brasil: a compreensão de uma produção intelectual; e conclui com os apontamentos finais. A intenção da análise não é recontar a obra, tampouco julgar se as ideias do autor estão adequadas ou inadequadas, mas ir além, compreender as razões de tais ideias, suas estratégias teórico-metodológicas e os discursos que utilizou no intento de alcançar os seus objetivos.

\section{A vida de Dermeval Saviani: a família, a infância e os estudos}

A vida de Dermeval Saviani se iniciou como grande parte da população brasileira que nasceu em uma cidade do interior na década de 1940 e advinha de uma família de lavradores. De acordo com sua autobiografia ${ }^{2}$ nasceu em uma fazenda, em Santo Antonio de Posse, que era Comarca de Mogi Mirim, no interior do Estado de São Paulo, no dia 25 de dezembro de 1943, entretanto devido às dificuldades de acesso a um cartório foi registrado no dia 03 de fevereiro de 1944, e é essa a data que consta no seu registro de nascimento para que seus pais não tivessem que pagar multa por ter ultrapassado o prazo de registro determinado na legislação da época. Percebe-se por meio de seus relatos que sua infância foi permeada pela penúria ${ }^{3}$ até que a família foi forçada pelas circunstâncias a se transferir para a capital em outubro de 1948.

Em São Paulo parece que a família, mesmo simples e humilde, saiu do estado de penúria na qual se encontrava no trabalho com a lavoura e se inseriu no mundo da fábrica ${ }^{4}$.

Dessa forma, com quatro anos de idade a criança Dermeval Saviani chega a São Paulo inserido em uma família de imigrantes italianos, que migram do âmbito rural para o âmbito urbano, composta de pai, mãe e oito filhos. E da inserção na problemática das dificuldades do homem do campo, cresce inserido na problemática do domem da fábrica. Sem dúvida esse contexto não pode ser desconsiderado, posteriormente nas suas opções acadêmicas e teórico-metodológicas.

O início da vida escolar de Saviani ocorreu aos oito anos de idade e parece que também não difere do início da vida escolar de muitos brasileiros. Iniciou seus estudos no curso primário do Grupo Escolar de Vila Invernada e lá permaneceu no período de 1951 a 1954. Avalia que essa instituição:

Pedagogicamente era uma escola tipicamente tradicional. Já não havia mais a palmatória, mas a régua, às vezes, desempenhava a mesma função. $\mathrm{O}$ diretor era uma figura temida. Os exames finais de cada série eram feitos na própria escola, mas não era a professora que formulava as questões e as aplicava. Esses exames eram feitos perante o inspetor do Estado. (SAVIANI, 2011, p. 02)

Quanto ao seu perfil de aluno, afirma: "não fui um aluno brilhante, mas logrei aprovação sem grandes dificuldades em todas as séries. Era um menino dócil, obediente, mas muito ativo" (Idem, Ibidem). E quanto a sua infância essa altivez fica expressa quando assegura que:

Durante o dia, quando não estava na escola estava na rua geralmente jogando bola. No futebol das peladas de rua era chamado de "maquininha" pela rapidez com que me desvencilhava das guaxumas, 
driblando e conduzindo a bola até o gol do adversário. Até aí minha infância foi, pois, como a de qualquer criança pobre, semelhante, portanto, à dos filhos da maioria da população que habita este país (Idem, Ibidem).

Em 1955, com onze anos de idade, ocorrem mudanças significativas na vida de Dermeval Saviani tanto no âmbito familiar como no escolar quando se separa da família e vai para Cuiabá, no Mato Grosso. Em sua autobiografia narra:

Iniciei o curso de admissão ao ginásio em 1955, na Paróquia de São Pio X e Santa Luzia, de Vila Leme, ainda em São Paulo, mas, em 27 de setembro do mesmo ano, segui com o vigário da referida paróquia para Cuiabá. Ali prestei exames de admissão ao ginásio no Liceu Salesiano São Gonçalo, tendo logrado aprovação em primeiro lugar. [...] A violência da ruptura foi sentida como se eu tivesse sido arrancado, com apenas onze anos de idade, de meu habitat, projetado nas nuvens (viajei de avião) e depositado num lugar inteiramente desconhecido. As dores da separação eu as sentia fisicamente. E acreditava (ou desejava?) estar doente, imaginando que assim poderiam me mandar de volta para casa. [...] O sentimento acima descrito com certeza terá deixado marcas indeléveis em minha vida. (SAVIANI, 2011, p. 02 e 03)

Nesse sentido, a tutela de um padre da igreja católica parece que foi determinante na vida escolar de Saviani. E esse aspecto não faz parte apenas de sua vida, como também de uma parte da população brasileira, já que naquele período essa era uma das formas de uma criança pobre ter acesso ao conhecimento.

Dos relatos de Saviani em sua autobiografia pode-se identificar a educação formal rigorosa a que foi submetido ${ }^{5}$ no Seminário Nossa Senhora da Conceição e no Seminário do Coração Eucarístico de Campo Grande, instituições nas quais estudou no período de 1955 a 1961, até concluir os estudos do Seminário Menor. Retorna para São Paulo em 1962, porém o curso de sua vida ainda seria trilhado em instituições religiosas católicas por um longo período.

De acordo com Vidal (2011) Saviani deu continuidade a sua formação no Seminário Maior, Seminário Central de Aparecida do Norte, no Estado de São Paulo em 1962, onde iniciou os seus estudos filosóficos, entretanto em 1963 é aprovado em Filosofia no vestibular da Faculdade Salesiana de Filosofia. Ciências e Letras de Lorena. Mas no final de 1963 abandona o Seminário ${ }^{6}$. Assim, em 1964 retorna à cidade de São Paulo, volta a morar com a família e transfere o curso de Filosofia para a Pontifícia Universidade Católica de São Paulo. Nesse período, associa os estudos ao trabalho no Banco Bandeirantes e posteriormente no Banco do Estado de São Paulo (Banespa) e à militância estudantil. Saviani (2011) assinala:

Na PUC participei da militância estudantil, onde já se punha de forma explícita a questão do Socialismo e já se manifestava alguma influência do marxismo. O curso de Filosofia ainda era dominantemente tomista, mas se fazia sentir aí uma visão mais atualizada, marcada principalmente pela influência da fenomenologia existencial. [...] Sendo de uma família operária, eu vivia num bairro periférico de São Paulo. Assim, nesses conturbados anos da década de 60, enquanto meu pai e meus irmãos participavam das greves nas fábricas e nas ruas, eu participava das assembléias e passeatas estudantis (2011, p. 5). 
Diante do que foi assinalado por Saviani é possível compreender que o então estudante de Filosofia se identificava com as ideias marxistas não somente no plano teórico, mas quiçá encontrasse explicações sociais para o seu contexto sócio-econômico e cultural no ideário marxista.

\section{A vida profissional e acadêmica: atividades profissionais, produções e publicações}

O início das atividades profissionais, na área da educação, de Saviani se deu, em conformidade com Vidal (2011, p. 8) em 1966 quando foi convidado pelo professor Joel Martins ${ }^{7}$ a atuar como monitor na disciplina de Filosofia da Educação, no curso de Pedagogia da PUC-SP, aos 22 anos. Desde modo, inicia a docência em Filosofia da Educação.

Outra influência significativa nas atividades profissionais e determinantes nas opções teórico-metodológicas de Saviani parece que foi a convivência com o professor Casemiro dos Reis Filho. Ele abaliza:

Quando comecei a lecionar, em 1967, o Prof. Casemiro dos Reis Filho foi contratado para a cadeira de Filosofia da Educação. [...] interagi muito fortemente com ele. Tínhamos contatos quase diários, inclusive tomando o mesmo ônibus entre o bairro das Perdizes, onde estava a sede da PUCSP, e o Ipiranga, onde ele morava. [...] Num desses momentos ele me disse: "Pois é; se você pretende, mesmo, seguir por esse caminho, você terá de enfrentar o estudo de Marx". E eu respondi, de imediato: "E qual é o problema?". Claro que eu já tinha alguns conhecimentos de Marx; mas, a partir daí, procurei fazer leituras mais sistemáticas, começando pelos "Manuscritos econômicos-filosóficos". Depois, a partir do final da década de 1970 e do início dos anos 1980, inclusive por solicitação dos alunos do doutorado, fiz uma leitura sistemática bastante completa de Gramsci e refiz a leitura de Marx desde os primeiros escritos até o capital. (SAVIANI, 2011, p. 35)

Todavia, para melhor vislumbre de sua vida profissional, apresenta-se o QUADRO 1:

\begin{tabular}{|l|l|}
\hline \multicolumn{3}{|l|}{ ATIVIDADES PROFISSIONAIS DE SAVIANI NA ÁREA DA EDUCAÇÃO } \\
DE 1966 A 2011 \\
\hline 1966 & $\begin{array}{l}\text { ATIVIDADE } \\
\text { Docência em Filosofia da Educação, como monitor da disciplina de Filosofia da } \\
\text { Educação, no curso de Pedagogia da PUC-SP. }\end{array}$ \\
\hline 1967 & $\begin{array}{l}\text { Assume a cadeira de Fundamentos Filosóficos da Educação no curso de Pedagogia da } \\
\text { PUC-SP, Professor de Filosofia no Colégio Estadual de São João Clímaco e de História e } \\
\text { Filosofia da Educação no Curso Normal do Colégio Sion. }\end{array}$ \\
\hline 1968 & $\begin{array}{l}\text { Demite-se do Banespa, assume também a disciplina de Filosofia da Educação na PUC-SP } \\
\text { e inicia a pesquisa para sua tese de doutorado. }\end{array}$ \\
\hline 1970 & $\begin{array}{l}\text { É aprovado em concurso público, assumindo, como efetivo, a cadeira de Filosofia do } \\
\text { Colégio e Escola Normal Estadual "Plínio Barreto, em São Paulo. }\end{array}$ \\
\hline 1971 & $\begin{array}{l}\text { Integra a equipe que montou a disciplina Introdução à Educação para o recém-instalado } \\
\text { Ciclo Básico de Ciências Humanas e Educação da PUC-SP e defende, seu doutorado, "O } \\
\text { conceito de sistema na Lei de Diretrizes e Bases da Educação Nacional” na mesma } \\
\text { instituição. }\end{array}$ \\
\hline 1972 & $\begin{array}{l}\text { Inicia as atividades nos Programas de Pós-Graduação em Filosofia da Educação da } \\
\text { Universidade Metodista de Piracicaba e na Pontifícia Universidade Católica de São } \\
\text { Paulo, em nível de mestrado. }\end{array}$ \\
\hline
\end{tabular}




\begin{tabular}{|c|c|}
\hline 1973 & É docente em tempo integral da PUC-SP até 1975. \\
\hline 1974 & $\begin{array}{l}\text { Começa a investigação "Funções de preservação e de deformação do Congresso Nacional } \\
\text { na legislação do ensino. }\end{array}$ \\
\hline $1975-1978$ & $\begin{array}{l}\text { É contratado como professor titular na Universidade Federal de São Carlos, onde formula } \\
\text { e implanta o curso de Pós-Graduação em Educação. Divide suas atividades docentes } \\
\text { entre a PUC-SP e a UFSCar. }\end{array}$ \\
\hline $1977-1979$ & $\begin{array}{l}\text { Desenvolve estudo das tendências e correntes pedagógicas na história da educação } \\
\text { brasileira, financiada pelo INEP. Viaja a convite da Universidade de Paris (Sorbonne) } \\
\text { para realizar estágio de pesquisa e efetua estágio de pesquisa também no Istituto } \\
\text { Gramsci, em Roma, em 1978. } \\
\text { Em } 1977 \text { é sócio fundador da Associação Nacional de Pós-Graduação e Pesquisa } \\
\text { (ANPEd) }\end{array}$ \\
\hline $1978-1979$ & $\begin{array}{l}\text { Em } 1978 \text { reassume o contrato em tempo integral na PUC-SP e passa a coordenar os } \\
\text { Programas de Mestrado em Filosofia da Educação e Doutorado em Educação. } \\
\text { Realiza intercâmbio acadêmico em instituições da Europa, integra o corpo editorial da } \\
\text { revista Educação e Sociedade, é sócio fundador de centro de estudos Educação e } \\
\text { Sociedade (CEDES) e da Associação Nacional de Educação (ANDE). }\end{array}$ \\
\hline 1980 & $\begin{array}{l}\text { Ingressa na UNICAMP, ministrando aulas na Graduação e Na Pós-Graduação em } \\
\text { Educação. }\end{array}$ \\
\hline 1981 & Integra o corpo editorial da Revista ANDE até 1994 \\
\hline 1982 & $\begin{array}{l}\text { Ministra em Buenos Aires a disciplina Teoria de la Educaciòn e retorna em } 1983 \text { e } 1985 \\
\text { na Facultad Latinoamericana de Ciencias Sociales. }\end{array}$ \\
\hline 1983 & $\begin{array}{l}\text { Desenvolve estudo das concepções de Filosofia da Educação presentes Revista Brasileira } \\
\text { de Estudos Pedagógicos até } 1984 \text {. Inicia as investigações sobre o Congresso Nacional e a } \\
\text { educação brasileira, com foco na análise do significado político da ação dos congressistas } \\
\text { na discussão e aprovação dos projetos das Leis } 4.024 / 61,5.540 / 68 \text { e } 5.692 / 71 \text {, base para } \\
\text { elaboração de sua tese de livre-docência, defendida em } 1986 \text {. }\end{array}$ \\
\hline 1984 & $\begin{array}{l}\text { Passa a integrar o Conselho Estadual de Educação de São Paulo, cargo que mantém até } \\
\text { 1997. Inicia a investigação "Pedagogia histórico-crítica". }\end{array}$ \\
\hline 1986 & $\begin{array}{l}\text { É aprovado em concurso público de livre-docência na disciplina História da Educação da } \\
\text { UNICAMP, tendo defendido a tese "O congresso nacional e a educação brasileira". } \\
\text { Participa do Seminário Interamericano sobre Educação, Desenvolvimento e Democracia, } \\
\text { realizado em Washington, D.C. - EUA. Cria a linha de pesquisa "História, Sociedade e } \\
\text { Educação no Brasil, origem do Grupo de Pesquisas HISTEDBR, institucionalizado em } \\
1991 \text {. }\end{array}$ \\
\hline 1987 & $\begin{array}{l}\text { Ministra na Universid de la República, em Montevidéu dois cursos intensivos sobre } \\
\text { "Correntes pedagógicas contemporâneas" e "Principais correntes pedagógicas e sua } \\
\text { aplicabilidade à realidade nacional" e profere conferência sobre o tema "Realidade e } \\
\text { perspectiva da educação no contexto latino-americano". }\end{array}$ \\
\hline 1989 & $\begin{array}{l}\text { Passa a regime de dedicação integral à docência e à pesquisa na UNICAMP, desligando- } \\
\text { se da PUC-SP. Inicia as investigações "História das ideias pedagógicas no Brasil" (I) e } \\
\text { "A nova Lei de Diretrizes e Bases da Educação Nacional". Torna-se coordenador de pós- } \\
\text { graduação da Faculdade de Educação até } 1992 \text {. }\end{array}$ \\
\hline 1990 & $\begin{array}{l}\text { É aprovado no concurso público de professor adjunto na disciplina História da Educação } \\
\text { da UNICAMP. Participa como docente do convênio estabelecido entre a UNICAMP e a } \\
\text { Universidade Estadual de Maringá. }\end{array}$ \\
\hline 1991 & $\begin{array}{l}\text { Formaliza, junto à Congregação da FE-UNICAMP, o Grupo de Estudos e Pesquisas } \\
\text { "História, Sociedade e Educação no Brasil" (HISTEDBR) que organiza, inicialmente, o } \\
\text { projeto "Levantamento e catalogação de fontes primárias e secundárias da educação } \\
\text { brasileira", ainda em funcionamento e com o apoio das instituições FAEP/UNICAMP, } \\
\text { INEP/MEC e CNPq. }\end{array}$ \\
\hline 1992 & $\begin{array}{l}\text { É indicado para o cargo de diretor associado da Faculdade de Educação, cargo que } \\
\text { ocupou até } 1996 .\end{array}$ \\
\hline 1993 & $\begin{array}{l}\text { É aprovado no concurso público para o cargo de professor titular da disciplina História } \\
\text { da Educação do Departamento de Filosofia e História da Educação do Departamento de } \\
\text { Filosofia e História da Educação da Faculdade de Educação da UNICAMP. }\end{array}$ \\
\hline 1994 & Vai até a Itália para realizar o projeto "A emergência da escola como forma principal e \\
\hline
\end{tabular}




\begin{tabular}{|c|c|}
\hline & $\begin{array}{l}\text { dominante de educação e o problema da formação de professores: um estudo de história } \\
\text { da educação em universidades italianas", com apoio de Bolsa Sênior-CNPq. Integra o } \\
\text { corpo editorial da Revista Comunicações (Piracicaba) }\end{array}$ \\
\hline 1995 & $\begin{array}{l}\text { Recebe a Medalha do Mérito Educacional do Ministério da Educação. Inicia a } \\
\text { investigação "Legislação complementar à LDB e o novo Plano Nacional de Educação. } \\
\text { Organiza, no âmbito do HISTEDBR, o Terceiro Seminário nacional, que chega em } 2009 \\
\text { à sua oitava edição. }\end{array}$ \\
\hline 1996 & $\begin{array}{l}\text { Inicia o projeto integrado de pesquisa "História das ideias Pedagógicas no Brasil" (II), } \\
\text { com apoio do CNPq, concluído em 2004. Integra o corpo editorial da Revista Brasileira } \\
\text { de Educação até 2000. Proponente e executor do Convênio de Cooperação entre a } \\
\text { UNICAMP e a Università degli studi di Padova (Itália) }\end{array}$ \\
\hline 1997 & $\begin{array}{l}\text { Recebe o Prêmio Zeferino Vaz de Reconhecimento Acadêmico pela produção científica } \\
\text { realizada entre } 1994 \text { e 1997, na UNICAMP. Participa como docente do convênio } \\
\text { estabelecido entre a UNICAMP e a Universidad Del centro de La Provincia de Buenos } \\
\text { Aires ministrando a disciplina Filosofia de la Educación Escolar. }\end{array}$ \\
\hline 1998 & $\begin{array}{l}\text { Integra o corpo editorial da revista História da Educação (UFPel) e Educação (UFSM). } \\
\text { Membro coordenador do Comitê Assessor de Educação do CNPq no período de 1998- } \\
1999 \text {. }\end{array}$ \\
\hline 1999 & $\begin{array}{l}\text { Assume a presidência da Sociedade Brasileira de História da Educação, cargo que ocupa } \\
\text { até 2001. Integra o corpo editorial da revista Cadernos de Pesquisa (Fundação Carlos } \\
\text { Chagas). }\end{array}$ \\
\hline 2000 & $\begin{array}{l}\text { Integra o corpo editorial das Revistas Diálogo Educacional (PUCPR), Linhas (UDESC), } \\
\text { Educação e Filosofia e até } 2005 \text { da Revista Brasileira de História da Educação. }\end{array}$ \\
\hline 2001 & $\begin{array}{l}\text { Aposenta-se pela UNICAMP após } 34 \text { anos de magistério e } 31 \text { anos de serviço público. } \\
\text { Mantém as orientações de TCC, iniciação científica, dissertações, teses e pós-doutorado. } \\
\text { Prossegue o projeto de pesquisa "História das Ideias Pedagógicas no Brasil", } \\
\text { articulado ao projeto integrado "Reconstrução histórica da escola pública no Brasil } \\
\text { (1870-1996)" no interior do grupo Nacional de Estudos e Pesquisas HISTEDBR, no qual } \\
\text { continua coordenador geral. }\end{array}$ \\
\hline 2002 & $\begin{array}{l}\text { Recebe o título de professor emérito, Universidade estadual de campinas - UNICAMP. } \\
\text { Assume um contrato de dois anos como professor titular colaborador na Faculdade de } \\
\text { Filosofia, Ciências e Letras de Ribeirão preto, da USP, dando início à investigação "O } \\
\text { espaço acadêmico da pedagogia no Brasil: perspectiva histórica e teórica", com o } \\
\text { financiamento do CNPq a partir de 2004. Integra o corpo editorial das revistas Educação } \\
\text { em Revista (UFMG) e Educação e Pesquisa (USP). Sob sua liderança o HISTEDBR } \\
\text { organiza as Jornadas Regionais, que em } 2011 \text { chegam à décima edição. }\end{array}$ \\
\hline 2003 & $\begin{array}{l}\text { Integra o corpo editorial da Revista Brasileira de Estudos Pedagógicos, de Espaço } \\
\text { Pedagógico e de Trabalho, Educação e Saúde. }\end{array}$ \\
\hline 2004 & Integra o corpo editorial da revista Educação e Linguagem. \\
\hline 2005 & $\begin{array}{l}\text { Integra o corpo editorial da Revista Ideação (Cascavel) e Revista Alpha (Patos de } \\
\text { Minas). }\end{array}$ \\
\hline 2006 & Integra o corpo editorial da Revista Percursos (UDESC) \\
\hline 2008 & $\begin{array}{l}\text { Recebe o Prêmio Jabuti de } 2008 \text { na categoria Educação, Psicologia e Psicanálise como } \\
\text { livro História das Idéias Pedagógicas no Brasil. }\end{array}$ \\
\hline 2009 & $\begin{array}{l}\text { Continua atuando como professor colaborador na Faculdade de Educação da UNICAMP, } \\
\text { oferecendo disciplinas e orientando trabalhos de mestrado, doutorado e pós-doutorado. }\end{array}$ \\
\hline 2010 & É agraciado com o título de pesquisador emérito do CNPq. \\
\hline
\end{tabular}

Fonte: Elaborado a partir das informações da Cronologia organizada por Vidal (2011) na obra Dermeval Saviani: pesquisador, professor e educador.

Ao analisar o QUADRO 1 pode-se considerar que Saviani desde que iniciou suas atividades profissionais viveu intensamente suas múltiplas facetas, atuando nos cursos de graduação e Programas de Pós-Graduação em Educação do Brasil,estabelecendo intercâmbio com instituições de outros países. Dessa forma, circula por várias instituições, 
entre as quais se destacam no Brasil a PUC-SP, a UFSCar e a UNICAMP; e no exterior a Universidad de La República em Montevidéu, a Universidad de La Provincia de Buenos Aires, a Facultad Latinoamericana de Ciencias Sociales de Buenos Aires, a Universidade de Paris (Sorbonne) e o Istituto Gramsci em Roma. Da mesma forma, integrou o corpo editorial de revistas significativas no meio acadêmico, como ANDE, História da Educação (UFPel), Educação (UFSM), Diálogo educacional (PUC-PR), Revista Brasileira de História da Educação, Cadernos de Pesquisa (Fundação Carlos Chagas), Revista Brasileira de Estudos pedagógicos, Revista Percursos (UDESC), entre outras.

Nesse sentido, Saviani ocupa um espaço privilegiado no meio acadêmico, na medida em que além da intensa circulação pelas instituições e editoriais de revistas acima descritos, foi presidente da Sociedade Brasileira de História da Educação de 1999 a 2001, é sócio fundador da Associação Nacional de Pós Graduação e Pesquisa (ANPEd) e criou a linha de pesquisa "História, Sociedade e Educação no Brasil", origem do já institucionalizado Grupo de Pesquisas HISTEDBR.

Outra consideração relevante derivada da análise do quadro 1 é que Saviani é um filósofo que circula prioritariamente pelas disciplinas de Filosofia da Educação e História da Educação, nos cursos de graduação e pós- graduação e consequentemente atua nos cursos de formação de professores e esse fato pode parcialmente explicar a grande aceitação que tem suas produções nesse âmbito. Isso aponta do mesmo modo para o fato de que "cada sociedade tem seu regime de verdade, sua 'política geral' de verdade; isto é, os tipos de discursos que ela acolhe e faz funcionar como verdadeiros" (FOUCAULT, 2004, p. 12)

Da mesma forma, não pode ser desconsiderado o fato de que Saviani esteve presente na formação de grande parte dos pesquisadores, ministrando disciplinas ou orientando diretamente os seus trabalhos. Vidal (2011, p.19) aponta que a primeira turma de doutorandos do Programa de Educação da PUC-SP era composta por Antonio Chizotti, Betty Antunes de Oliveira, Bruno Pucci, Carlos Roberto Jamil Cury, Fernando José de Almeida, Guiomar Namo de Mello, Luiz Antonio Cunha, Mirian Jorge Warde, Neidson Rodrigues, Osmar Fávero e Paolo Nosella e nos grupos subseqüentes estariam, dentre outros, José Carlos Libâneo, Gaudêncio Frigotto, Maria Elizabete Prado Xavier, Sandino Hoff e Paulo Ghiraldelli Jr. E dentre todos, Saviani foi o orientador de Oliveira, Namo de Mello, Cunha, Warde, Nosella, Fávero, Rodrigues, Cury, Frigoto, Xavier, Ghiraldelli e Libâneo. Saviani:

Diante disso, apresenta-se o QUADRO 2 que diz respeito às publicações de

\begin{tabular}{|l|l|}
\hline \multicolumn{2}{|c|}{ PUBLICAÇÕES DE SAVIANI NO PERÍODO DE 1973 a 2011} \\
\hline ANO & PUBLICAÇÕES \\
\hline 1973 & $\begin{array}{l}\text { Sua tese com o título modificado para "Educação brasileira: estrutura e sistema". Editoras: } \\
\text { Saraiva, Cortez e Autores Associados. }\end{array}$ \\
\hline 1977 & "Educação brasileira contemporânea" (em coautoria). \\
\hline 1980 & "Educação: do senso comum à consciência filosófica". Editoras: Cortez/ Autores Associados. \\
\hline 1982 & $\begin{array}{l}\text { "Anseinandersetzung unter christen". Publik-Forun, 07, 11 abr. 1982 e "Paulo Freire: Christ } \\
\text { oder Agnostiker?" Forum, v. 56, 1982, contrapondo-se à crítica de D. Vicente Scherer, cardeal } \\
\text { de Porto Alegre, publicada na Alemanha. }\end{array}$ \\
\hline 1983 & $\begin{array}{l}\text { "Escola e Democracia", traduzido para o espanhol em 1988, editoras: Cortez, Autores } \\
\text { Associados e Monte Sexto. "Filosofia da Educação Brasileira" em coautoria, editora } \\
\text { Civilização Brasileira. "Desenvolvimento educacional na América Latina", editoras: Cortez e } \\
\text { Autores Associados. }\end{array}$ \\
\hline 1984 & "Ensino Público e algumas falas sobre universidade". Editoras: Cortez e Autores Associados. \\
\hline 1987 & "Política e educação no Brasil", Editora Autores Associados. \\
\hline
\end{tabular}




\begin{tabular}{|c|c|}
\hline 1989 & "Sobre a concepção de politecnia". Editora Fundação Osvaldo Cruz \\
\hline 1991 & $\begin{array}{l}\text { "Pedagogia histórico-crítica". Editoras: Cortez e Autores Associados. "Educación: temas de } \\
\text { actualidad" em Buenos Aires, pela editora Libros Del quirquincho versão em espanhol de } \\
\text { "Educação e questões da atualidade", publicado pelas editoras Cortez e Livros do Tatu. }\end{array}$ \\
\hline 1994 & $\begin{array}{l}\text { Artigos nas revistas italianas La Didattica, Richerche Pedagogiche, Infanzia, Prospettiva-EP; } \\
\text { Scuola-SE. }\end{array}$ \\
\hline 1996 & "Para uma história da educação latino-americana" (organizador), Editora Autores Associados. \\
\hline 1997 & "A nova lei da educação (LDB): trajetória, limites e perspectivas, Editora Autores Associados. \\
\hline 1998 & $\begin{array}{l}\text { "Da nova LDB ao novo Plano Nacional de Educação: por uma outra política educacional", } \\
\text { Editora Autores Associados. "Formação de professores: a experiência internacional sob o } \\
\text { olhar brasileiro" (organizador), Editora Autores Associados. }\end{array}$ \\
\hline 1999 & $\begin{array}{l}\text { "História da Educação: perspectivas para um intercâmbio internacional" (organizador), Editora } \\
\text { Autores Associados. }\end{array}$ \\
\hline 2003 & $\begin{array}{l}\text { "Intelectual educador mestre: presença do Professor Casemiro dos Reis Filho, na educação } \\
\text { brasileira" (organizador), Editora Autores Associados. }\end{array}$ \\
\hline 2004 & $\begin{array}{l}\text { "O legado educacional do século XX no Brasil" (em coautoria), Editora Autores Associados. } \\
\text { Histórias e memórias da educação no Brasil (em coautoria), Editora Vozes. }\end{array}$ \\
\hline 2005 & $\begin{array}{l}\text { Organizador das obras: "A escola pública no Brasil: história e historiografia", "marxismo e } \\
\text { educação: debates contemporâneos", "Capitalismo, trabalho e educação", "História e História } \\
\text { da Educação: o debate teórico metodológico atual", publicadas pela Editora Autores } \\
\text { Associados. Em coautoria: "História da educação brasileira: formação do campo", Editora } \\
\text { Unijuí. }\end{array}$ \\
\hline 2006 & "O legado educacional do século XXI" (em coautoria), Editora Autores Associados. \\
\hline 2007 & $\begin{array}{l}\text { "Da nova LDB ao FUNDEB", "História das ideias pedagógicas no Brasil", e "Instituições } \\
\text { escolares no Brasil: conceito e reconstrução histórica" (organizador), Editora Autores } \\
\text { Associados. }\end{array}$ \\
\hline 2008 & $\begin{array}{l}\text { "A pedagogia no Brasil: história e teoria", Editora Autores Associados e em coautoria } \\
\text { "Educação na história", Editora UEMA. }\end{array}$ \\
\hline 2009 & $\begin{array}{l}\text { "PDE - Plano de desenvolvimento da Educação: análise crítica da política do MEC", Editora } \\
\text { Autores Associados e em coautoria "Conferência Nacional de Educação (Conae) 2010, Editora } \\
\text { INEP/MEC }\end{array}$ \\
\hline 2010 & $\begin{array}{l}\text { "Interlocuções pedagógicas: conversa com Paulo Freire e Adriano Nogueira e } 30 \text { entrevistas } \\
\text { sobre educação" e "Escuela y Democracia, Editora Autores Associados. Em coautoria: "A } \\
\text { organização do trabalho didático na história da educação", Editora Autores Associados e } \\
\text { "Desenvolvimento: ideias para um projeto nacional", Editora Anita Garibaldi/Fundação } \\
\text { Maurício Grabois. }\end{array}$ \\
\hline 2011 & $\begin{array}{l}\text { "Educação em diálogo", Editora Autores Asociados; em coautoria "Pedagogia histórico- } \\
\text { crítica: } 30 \text { anos", Editora Autores Associados e "Estado e políticas educacionais na história da } \\
\text { educação brasileira", Editora EDUFES. }\end{array}$ \\
\hline
\end{tabular}

QUADRO 2 - PUBLICAÇÕES DE SAVIANI NO PERÍODO DE 1973 a 2011

Fonte: Elaborado a partir das informações da Cronologia organizada por Vidal (2011) na obra Dermeval Saviani: pesquisador, professor e educador.

Da mesma forma que suas atividades profissionais e acadêmicas as publicações de Saviani são igualmente intensas. É indispensável ressaltar que a maioria dessas publicações teve, provavelmente, como público alvo de suas ideias, os professores. O que foi verificado quanto as suas atividades profissionais está refletido nas suas publicações que tentam dar conta da Filosofia da Educação, da História da Educação, da Didática, da Prática pedagógica e das Políticas Educacionais.

Nessa direção, o seu livro mais polêmico e mais vendido foi e ainda é Escola e Democracia que está na $41^{a}$ edição e foi traduzido para o espanhol em 1988. Nesse livro Saviani polemiza ao abordar a "teoria da curvatura da vara" 8 que da origem a outros textos que propõem uma nova proposta pedagógica que ele denomina a partir de 1984 de "Pedagogia histórico-crítica" 9 . 
Ao analisarmos o seu percurso acadêmico, que como vimos no QUADRO 1 é bastante intenso, e dos cargos que assumiu durante a sua vida profissional Saviani justifica a aceitaçãoda candidatura à coordenação da Pós-Graduaçãoda UNICAMP ao se utilizar de Maquiavel de uma forma muito particular:

Assim, apliquei a mim mesmo a máxima de Maquiavel: o bem, faça-o aos poucos; o mal, faça tudo de uma vez. Como considerava que para mim era um grande mal assumir funções administrativas, resolvi dar logo minha cota e aceitei a coordenação. (2011, p. 47)

Quanto à constituição de uma família ${ }^{10}$ Dermeval Saviani demonstra um afã tardio, casou-se pela primeira vez, e mantém este matrimônio, com Maria Aparecida Dellinghausen Motta em 1984 e em 1988 nasceu seu filho Benjamim Motta Saviani. E é a eles que afetuosamente ${ }^{11}$ dedica a obra "História das ideias pedagógicas no Brasil", objeto da análise a seguir...

\section{A obra História das Ideias Pedagógicas no Brasil: a compreensão de uma produção intelectual}

A obra História das Ideias Pedagógicas no Brasil, foi publicada em $1^{\mathrm{a}}$ edição no ano de 2007 e segundo o autor ${ }^{12}$ em menos de um ano, esgotou-se a primeira edição. E como observamos, no quadro 2, recebeu o Prêmio Jabuti ${ }^{13}$ de 2008 na categoria Educação, Psicologia e Psicanálise. Na sua $2^{a}$ edição ela foi revista e ampliada pelo autor e é esta edição que aqui se analisa. Nesse sentido, a obra possui 8 páginas iniciais, 4 páginas de sumário, 4 páginas de lista de siglas, 2 páginas de prefácio à segunda edição, 4 páginas de prefácio da $1^{\mathrm{a}}$ edição. $\mathrm{O}$ contéudo vai da página 1 (introdução) até a página 451, seguido das referências que se estendem até a página 474.

Em relação aos aspectos físicos da obra, merecem destaque a qualidade do aspecto gráfico, a capa dura em cores harmônicas, as páginas com papel de qualidade e as imagens em preto e branco, porém com uma resolução de qualidade. Entretanto, as 40 imagens não foram tomadas enquanto fontes, mas utilizadas apenas como meras ilustrações.

O conteúdo da obra está distribuído em introdução; primeiro período - as ideias pedagógicas no brasil entre 1549 e 1759: monopólio da vertente religiosa da pedagogia tradicional, composto pelos capítulos I (colonização e educação), II (uma pedagogia brasílica) e III (a institucionalização da pedagogia jesuítica ou o Ratio Studiorum; segundo período - as ideias pedagógicas no brasil entre 1759 e 1932: coexistência entre as vertentes religiosa e leiga da pedagogia tradicional, composto pelos capítulos IV (a "máquina mercante" e as metamorfoses na educação), V (as ideias pedagógicas do despotismo esclarecido) e VI (Desenvolvimento das ideias pedagógicas leigas: ecletismo, liberalismo e positivismo) ; terceiro período - as ideias pedagógicas no Brasil entre 1932 e 1969: predomínio da pedagogia nova, composto pelos capítulos VII (fordismo, keynesianismo e a nova educação), VIII (equilíbrio entre a pedagogia tradicional e a pedagogia nova), IX (predominância da pedagogia nova) e X (crise da pedagogia nova e articulação da pedagogia tecnicista); quarto período - as ideias pedagógicas no brasil entre 1969 e 2011: configuração da concepção pedagógica produtivista, composto pelos capítulos XI (a educação na ruptura política para a continuidade socioeconômica), XII (pedagogia tecnicista, concepção analítica e visão crítico-reprodutivista), XIII (ensaios contrahegemônicos: as pedagogias críticas buscando orientar a prática educativa) e XIV ( o 
neopositivismo e suas variantes: neo-escolanovismo, neoconstrutivismo, neotecnicismo); conclusão e referências bibliográficas.

Desta forma, a estrutura da obra está dividida em quatro períodos, analisados de forma linear onde é possível perceber, aquilo que percebeu Alves (2008, p. 178), isto é, o autor inicia cada período com a contextualização histórica geral no qual o autor procura identificar as mudanças e permanências percebidas, posteriormente nas ideias pedagógicas. No entanto, essa estratégia parece ser usual desde os primeiros manuais de história da educação escritos no Brasil ${ }^{14}$.

A obra é resultado, conforme observamos no quadro 1, de um amplo projeto de pesquisa que iniciou no ano de 1989 e que em 2001 estava articulado ao projeto integrado "Reconstrução histórica da escola pública no Brasil (1870-1996)" no interior do grupo Nacional de Estudos e Pesquisas HISTEDBR.

A análise do desenvolvimento dos capítulos permite perceber que há pouco ineditismo na obra, as produções anteriores do autor são utilizadas recorrentemente em todos os capítulos. Saviani optou assim, por um estudo sintético que é justificado pelo autor $^{15}$ como uma forma de incorporar o conhecimento como objeto de ensino:

Resulta pertinente, portanto, indagar sobre o grau em que as investigações são suscetíveis de se integrarem aos programas de ensino próprios das disciplinas escolares. [...] Ora, nós sabemos que nos últimos anos têm prevalecido, nas pesquisas histórico-educativas realizadas em nosso país, as análises específicas caracterizadas por recortes particulares, via de regra microscópicos, dos objetos da história da educação. Parece, pois, de grande relevância a realização de estudos sintéticos, uma vez que é a partir deles que os avanços no campo da pesquisa poderão integrar os programas escolares viabilizando a sua socialização e, em conseqüência, a elevação do nível de conhecimento da nossa história pela população. (SAVIANI, 2011, p. xviii)

Nessa mesma direção, Saviani não fez a opção pela análise das fontes em diálogo com os autores que abordam as temáticas, tampouco se preocupa em apresentar fontes inéditas, preferiu utilizar-se de fontes já disponíveis e dos trabalhos que foram produzidos por outros pesquisadores. Afirma que:

Foi com esse espírito que projetei a pesquisa sobre a história das ideias pedagógicas no Brasil, incidindo mais sobre a síntese do que sobre a análise. Assim, em lugar de se dar precedência à descoberta de fontes ainda não exploradas visando a produzir análises de momentos específicos da história da educação brasileira, buscou-se a partir das fontes disponíveis, construir sínteses explicativas de amplo alcance. Em razão do objetivo apontado é que a proposta se situou no âmbito do tempo longo, procurando cobrir todo o espectro da história das ideias pedagógicas no Brasil (SAVIANI, 2008, p. xviii).

Saviani (2011) deixa claro no prefácio que a intenção da obra é que "venha a permitir a incorporação dos resultados da investigação nos programas escolares a serem trabalhados pelos professores nas salas de aula". E reforça: "foi, pois, pensando nos professores que escrevi este livro" e ainda "todo o corpo do livro pretende constituir-se em subsídio para o trabalho dos professores". Para o autor a obra: 
Põe-se como um roteiro para o estudo, que pode atingir diferentes níveis de aprofundamento, da educação brasileira, o professor pode tomar este livro como texto-base, prevendo um maior nível de aprofundamento de cada período ou de cada fase, organizando seminários com grupos de alunos. Nesse caso poderá recomendar, a cada grupo de alunos, leituras adicionais correspondentes ao período ou fase escolhida, lançando mão das referências bibliográficas respectivas. (SAVIANI, 2008, p. xix)

No entanto o que poderia estar indicando Saviani ao afirmar que o "livro é um primeiro esforço no sentido de colocar ao alcance dos professores um recurso que lhes permita abordar a educação brasileira em seu conjunto, desde as origens até nossos dias" e que "como tal ele não poderia ser exaustivo"?

Diante disso, parece que Saviani quer identificar a obra como uma pioneira ao "didatizar" a História da Educação para que sua leitura não fique exaustiva para os professores. Portanto ao indicar que a obra é para ser abordada em sala de aula, pode conduzir à interpretação de que a sua escrita é prioritariamente para alunos e professores do curso de pedagogia e não para os seus interlocutores da História e da Historiografia da Educação.

Nesse sentido, após o lançamento da $1^{\text {a }}$ edição de "história das ideias pedagógicas no Brasil", Ghiraldelli Jr. (2008) tece críticas incisivas à abordagem de seu outrora orientador e chega até mesmo a afirmar que se levasse a crítica para o campo metodológico da história da educação a sua produção seria uma obra paradidática.

Saviani assinala (2011, p. 1-2) que o objeto próprio do livro é a exposição das ideias pedagógicas em sua trajetória pela história da educação brasileira e que a investigação realizada veio preencher uma lacuna no domínio dos conhecimentos pedagógicos na medida em que pretendeu atingir uma síntese compreensiva, crítica e sistematizada da evolução das ideias pedagógicas em nosso país desde suas origens até os dias atuais.

A síntese anunciada por Saviani certamente advém de suas opções teóricometodológicas, marcadamente marxistas. No entanto, ele parece tentar superar parcialmente, pelo menos no plano teórico, algumas dessas marcas ao afirmar que:

A perspectiva teórico-metodológica que orientou a pesquisa pode ser caracterizada, suscintamente, nos seguintes termos: esforço de superação dos limites dos paradigmas tradicionais da historiografia representados pelo positivismo e presentismo (Schaff, 1974), em interlocução ativa e crítica com as correntes atuais que resultaram das contribuições da "Escola dos Annales" (Burke, 1991) e que se difundiram sob a denominação "História Nova" (Le Goff, 1990). Nessa interlocução procurei manter-me atento aos riscos de relativismo ou irracionalismo presentes nas novas tendências, conforme transparece nos debates teórico-metodológicos sobre a historiografia atual (Cardoso, 1994, 1997; Dosse, 1992). (SAVIANI, 2008, p. 3)

Entretanto, ao apontar as suas considerações sobre o conhecimento, assinala que:

O conhecimento em geral e, especificamente, o conhecimento histórico educacional configura um movimento que parte do todo caótico (síncrese) e atinge, por meio da abstração (análise), o todo concreto (síntese). Assim, o conhecimento que cabe à historiografia educacional produzir consiste em reconstruir, por meio das ferramentas conceituais 
(categorias) apropriadas, as relações reais que caracterizam a educação como um fenômeno concreto, isto é, como uma "rica totalidade de elações e determinações numerosas" (Marx, 1973, pp. 228-237). (SAVIANI, 2008, p.03)

Nesse sentido, Saviani não consegue se desvencilhar dos pressupostos marxistas. Por mais que ele cite outros autores e construa a sua obra embasada em diferentes autores, não marxistas, a concepção que ele tem de conhecimento faz com que uma pesquisa que durou mais de uma década, se transforme numa síntese quando poderia ter resultado em uma análise aprofundada.

Para dar sustentabilidade à sua concepção de conhecimento histórico-educacional Saviani (2008, p. 3-4) cita cinco diretrizes teórico-metodológicas que seriam: o princípio do caráter concreto do conhecimento histórico-educacional relacionado à exigência de explicitar o grau em que o objeto da investigação expressa a complexidade das relações e determinações próprias da educação brasileira ao longo de sua história; o princípio da efetivação de uma perspectiva de longa duração, enfatizado pela "Escola dos Annales" por Braudel, mas que fez parte também da orientação metodológica proposta por Gramsci; o princípio do olhar analítico-sintético no trato com as fontes de forma que não deixe escapar as características e o significado do fenômeno investigado; o princípio da articulação do singular e do universal, garantindo-se que no exame das fontes se encontre a justa relação entre o local, o nacional e o internacional; e finalmente o princípio da atualidade da pesquisa histórica, que implica na consciência de que, como toda pesquisa, a investigação histórica não é desinteressada. No que diz respeito ao este último princípio, Saviani (2008) afirma ainda que:

Consequentemente, o que provoca o impulso investigativo é a necessidade de responder a alguma questão que nos interpela na realidade presente. Obviamente isso não tem a ver com "presentismo" nem mesmo com o "pragmatismo". Trata-se da própria consciência da historicidade humana, isto é, a percepção de que o presente se enraíza no passado e se projeta no futuro. (p. 4)

Diante desses princípios, se percebe que esta obra é resultado de opções teóricometodológicas que não desconsidera o público para o qual ela foi produzida, mas que reflete as orientações ideológicas do autor. E que o autor já se antecipa às possíveis críticas da presença de "presentismo" e "pragmatismo" que a obra possa despertar.

Outra marca abstrusa de ser superada em Saviani (2011) é o método filosófico. Ele afirma que seu método é "de caráter historiográfico", entretanto prossegue afirmando que "como o que se fez foi uma história das ideias, a atitude adotada tem afinidades com os procedimentos utilizados nos estudos filosóficos, situando-se naquele âmbito que Goldmann (1967) denominou 'História da Cultura'”. (p. 5)

No decorrer da obra, Saviani recorta das 354 referências bibliográficas ${ }^{16}$ a idéia de vários autores para compor a sua escrita, indiscriminadamente, sem atentar para possíveis incompatibilidades teórico-metodológicas.

Nesse sentido, o autor utiliza-se de um ecletismo nem sempre compatível para justificar as suas escolhas. Assim é que tenta dar sustentabilidade à sua "História das ideias pedagógicas no Brasil" citando, entre outros Braudel, Gramsci, Burke, Le Goff, Dosse, Marx e Durkheim. Nesse sentido, ele aponta entre outras questões o problema teórico enfrentado no curso da investigação referente à própria expressão "história das ideias pedagógicas" 17 e faz distinção entre ideias educacionais e ideias pedagógicas: 
Por ideias educacionais entendo as ideias referidas à educação, quer sejam elas decorrentes da análise do fenômeno educativo visando a explicá-lo, quer sejam elas derivadas de determinada concepção de homem, mundo ou sociedade sob cuja luz se interpreta o fenômeno educativo. [...] Por ideias pedagógicas entendo as ideias educacionais, não em si mesmas, mas na forma como se encarnam no movimento real da educação, orientando e, mais do que isso, constituindo a própria substância da prática educativa. [...] De qualquer modo, tal definição pões em evidência a estreita ligação entre as ideias pedagógicas e a prática educativa. (SAVIANI, 2008, p. 6-7)

Ao justificar sua opção pela longa duração, cita Braudel ${ }^{18}$ e Gramsci $^{19}$, entretanto depois de uma longa digressão afirma que:

Com essa digressão em torno das posições de Braudel e Gramsci, espero ter deixado clara a razão de ter considerado mais feliz a abordagem de Gramsci, já que, segundo meu entendimento, este último sugere uma metodologia que permite dar conta mais satisfatoriamente da história como um processo cujo movimento necessita ser reconstruído pelo historiador (SAVIANI, 2008, p. 11).

Para justificar a sua periodização Saviani (2008) conclui que:

O princípio de periodização que guiou a distribuição das ideias pedagógicas nos períodos indicados se baseia na noção de predominância ou hegemonia. Ou seja, a cada período corresponde a predominância de determinadas ideias pedagógicas, sendo isso o que diferencia os períodos entre si. Obviamente, essa forma de periodizar não deve excluir as ideias não-predominantes, mesmo aquelas que jamais puderam sequer aspirar a alguma hegemonia. A história das ideias pedagógicas precisa, pois, incorporá-las em algum grau. (p. 20)

A linguagem marxista aparece recorrentemente na obra com a utilização de termos, como dominados, dominantes e burguesia, como também as inúmeras citações e diálogos com Marx. É assim que no Capítulo I - Colonização e educação, conclui com uma ideia de Marx:

Assim, se Marx (1968, PP 90-91, nota 33; 1985, p. 115) pôde dizer que, para os teólogos, a sua própria religião é considerada obra de Deus, ao passo que a religião dos outros é obra dos homens, para os jesuítas a religião católica era considerada obra de Deus, enquanto as religiões dos índios e dos negros vindos da África eram obra do demônio.(SAVIANI, 2008, p. 47)

Nessa direção, Nunes abaliza que:

Uma leitura dogmática e simplificadora do marxismo, predominantemente nos cursos de pós-graduação em educação, contribuiu para criar uma estratégia discursiva que, associada a certos aspectos de retórica - o abuso do recurso da utilização do argumento de autoridade e a repetição contínua de certas expressões polarizadas, como, por exemplo, "dominados e dominantes", "conservadores e transformadores" -, criaram uma espécie de caixa de eco capaz de 
reforçar as convicções de quem escreve e extrapolar os limites da argumentação, tornando-se uma camisa-de-força que enquadra rigidamente a empiria na teoria. (1996, p. 77)

No capítulo VIII - Equilíbrio entre a pedagogia tradicional e a pedagogia nova (1932-1947) opta pela abordagem das ideias de três intelectuais: Lourenço Filho, Fernando de Azevedo e Anísio Teixeira e utiliza a designação "trindade cardinalícia" (p. 207). No mesmo sentido utiliza as denominações "trindade católica" para Alceu Amoroso Lima, padre Leonel Franca e cardeal Leme e "trindade governamental" para Getúlio Vargas, Francisco Campos e Gustavo Capanema (p. 265). No entanto, ao analisar o sentido de cardinalício no dicionário de língua portuguesa ${ }^{20}$, parece que o termo não adquire sentido, quiçá fosse mais adequado o termo cardinal ${ }^{21}$.

Outro aspecto a se considerar no capítulo VIII é que Saviani omite algumas de suas considerações sobre a Escola Nova, expostas em outras publicações, como Escola e Democracia. Parece que o autor ponderou as suas ideias e não guarda nenhum rancor das críticas contundentes realizadas por Zaia Brandão já que citou um trecho do mesmo texto de Brandão em sua obra, para se referir a Paschoal Lemme. Em relação à análise anterior de Saviani, Brandão assinalou que:

O problema deste tipo de análise é o de trabalhar no horizonte da substituição da memória-legada, pelo seu avesso: uma espécie de memória-negada. [...] Quero registrar diretamente o caráter abstrato e desistoricizado dessa versão da historiografia. [...] Saviani neste texto acaba por apagar todas as diferenças. Ambigüidades e contradições que atravessaram a história do movimento de escola nova, entre, nós. (BRANDÃO, 1999, p.40-46)

Entretanto, foi a polêmica diante da "teoria da curvatura da vara" e posteriormente do texto "para além da curvatura da vara" que deram origem ao seu livro mais vendido e a sua "pedagogia histórico-crítica".

A recorrência às obras já produzidas pelo autor parece ter um caráter de marcar a sua presença como participante e produtor da história da educação brasileira. Isso fica evidente quando expõe uma fotografia sua, aos 12 anos, em uma sala de aula do $1^{\circ}$ ano ginasial do Seminário Nossa Senhora da Conceição de Cuiabá para ilustrar o item "O conflito escola particular versus escola pública" (p. 284-285).

No capítulo XIII, na abordagem dos "Ensaios contra-hegemônicos: as pedagogias críticas buscando orientar a prática educativa (1980-1991)", Saviani alude às pedagogias contra-hegemônicas, entre as quais está a "pedagogia histórico-crítica", teoria da qual ele é o formulador. Entretanto, ele se restringe a citar a si próprio sem aprofundamento na análise das "ideias pedagógicas" formuladas.

Em alguns trechos da obra percebe-se que o autor responde a possíveis críticas, como quando escreve sobre as ideias de Paulo Freire:

Referi-me a essa proposta em meu livro Escola e democracia como a uma espécie de "Escola Nova Popular". Alguns analistas viram nessa referência uma crítica negativa quando, em verdade, ela traduz o reconhecimento do caráter inovador e da importância social, política e pedagógica de Paulo Freire na história da educação brasileira. (SAVIANI, 2008, p. 335) 
Nesse sentido, Ghiraldelli Jr. (2008) assinala que:

os capítulos sobre Lauro de Oliveira Lima e Paulo Freire parecem enfiados ali a fórceps, quase que como uma obrigação. Teria sido uma obrigação vinda da literatura dos manuais existentes que, ao contrário dos textos de Saviani, não deram tão pouca importância a esses educadores como ele nos seus escritos dos anos 80 ?

Diante da obra como um todo cabe apontar a percepção de que os três primeiros períodos demonstram um maior esforço de análise, reflexão e diálogo com a história e a historiografia da educação do que o quarto período. Para Maria Dativa de Salles Gonçalves (2009):

Enquanto as análises dos três primeiros períodos, mais distantes do movimento atual, permitem uma compreensão aprofundada dos movimentos "orgânicos e conjunturais", o mesmo não parece ocorrer em relação ao quarto período, especialmente nos cap. 13 e 14. (p. 323)

Nessa mesma direção, parece que a proximidade com o tempo presente ofuscou até mesmo os pressupostos teórico-metodológicos apontados por Saviani quando afirma a opção pelos "movimentos orgânicos e conjunturais" de Gramsci. Saviani teria caído na armadilha apontada por ele próprio ao expor sua metodologia ao trabalhar com a sua primeira hipótese de periodização? Sua preocupação é a de que:

[...] estaria incorrendo no risco apontado por Gramsci (1975, p.1580), para quem "o erro no qual se cai frequentemente nas análises históricopolíticas consiste em não saber encontrar a justa relação entre o que é orgânico e o que é ocasional”. (SAVIANI, 2011, p. 18)

Diante disso, parece que no Brasil a tentativa de compreensão e aplicação das ideias de Gramsci tem sido problemática. Vieira (1999, p. 53) identifica problemas metodológicos na interpretação das ideias gramscianas, na medida em que seu pensamento, no plano acadêmico e político brasileiro, nas décadas de setenta e de oitenta, foi um fenômeno de grande proporção, no qual conceitos como hegemonia, bloco histórico, intelectuais orgânicos, foram introduzidos nos debates nas mais diversas situações, bem como reivindicados por diferentes vertentes do pensamento político e acadêmico brasileiro, resultando na constatação de que as categorias gramscianas, foram "instrumentalizadas" e formalizadas, tornando-se "onicompreensivas". Assim, como se não bastasse ser incompreendido na sua proposição historicista, Gramsci foi "instrumentalizado" como pensador de categorias, ou melhor, de fórmulas "aistóricas" de compreensão do real. Deste modo, o autor aponta que a rejeição de uma interpretação formalista do pensamento gramsciano continua atual e deve ser reafirmada para impedir "as simplificações teóricas que, muito mais que esterilizar o pensamento de um autor, contribuem para a esterilização do procedimento científico".

\section{Apontamentos finais}

Mesmo diante das problematizações da obra, na tentativa de compreendê-la, não há como ignorar a grande contribuição de Dermeval Saviani para os Programas de PósGraduação no Brasil e o contributo da obra "Histórias das ideias pedagógicas" para os cursos de formação de professores. Não se desconsidera que essa afirmação possa ser 
interpretada por alguns como o problema do "terreno do consenso" ${ }^{22}$ existente nos Programas de Pós-Graduação do Brasil, já que até mesmo o mais contundente de seus críticos, o outrora orientando de Saviani, Ghiraldelli $\mathrm{Jr}^{23}$, admite a pertinência da obra.

A grande aceitação e repercussão da atuação, das produções e das publicações de Saviani se expressa no fato de que, como se observa no QUADRO 1, em 1995 recebe a medalha do Mérito Educacional do Ministério da Educação; em 1997 recebe o Prêmio Zeferino Vaz de Reconhecimento acadêmico pela produção científica realizada entre 1994 e 1997, na UNICAMP; em 2002 recebeu o título de professor emérito da UNICAMP; e em 2010 é agraciado com o título de pesquisador emérito do CNPq.

Nesse sentido, para compreender a escrita da História da Educação deSaviani se tem que analisar o motivo que o levou a se enveredar pelos caminhos da História da Educação. O autor afirma que:

[...]o fator decisivo que me levou a enveredar pelos caminhos da História e da Historiografia foi a minha concepção de Filosofia. Como rapidamente evoluí em minha formação filosófica para a concepção dialética e, em seguida, mais especificamente para o materialismo histórico, a História se impôs como o território onde eu tinha de me mover necessariamente. (VIDAL, 2011, p. 31)

Diante disso, é possível concluir que a obra "História das ideias pedagógicas no Brasil" tem a marca filosófica e marxista das opções ideológicas e teórico-metodológicas de Saviani. No entanto,é plausívelafirmar que indubitavelmente Dermeval Saviani é um dos maiores intelectuais contemporâneos no Brasil.Não há como colocar em dúvida a grandeza de sua atuação enquanto escritor, filósofo, professor, pesquisador, educador e ativista pela História da Educação.

\section{REFERÊNCIAS}

BRANDÃO, Zaia. A Intelligentsia educacional - Um percurso com Paschoal Lemme por entre as memórias e as histórias da Escola Nova no Brasil. Bragança Paulista: IFANCDAPH. Editora da Universidade São Francisco/EDUSF, 1999.

BONTEMPI JUNIOR, Bruno. História da Educação Brasileira: o terreno do consenso. In: FREITAS, Marcos Cezar (Org.). Memória intelectual da Educação Brasileira. Bragança Paulista: EDUSF, 1999.

BLOCH, Marc. Apologia da história ou o ofício do historiador. Rio de Janeiro: Jorge Zahar, 2001.

EDITORA EDUCACIONAL BRASILEIRA S.A. Moderno dicionário enciclopédico Brasileiro. Curitiba: Editora Educacional Brasileira S.A, 1986.

FOUCAULT, Michel. Verdade e Poder. In: Microfísica do Poder. Rio de Janeiro: Edições Graal, 2004. 
GHIRALDELLI JR, Paulo. As ideias pedagógicas historiadas por Saviani. Disponível em http://ghiraldelli.wordpress.com/2008/02/09/as-ideias-pedagogicas-historiadas-porsaviani/. Acesso em 05/12/2011.

LUFT, Celso Pedro. Minidicionário Luft. São Paulo: Ática, 2000.

NUNES, Clarice. Ensino e historiografia da educação: problematização de uma hipótese. Revista Brasileira de Educação, n. 01, p. 67-79, 1996.

PEIXOTO, Afrânio. Noções de História da Educação. Rio de Janeiro: Companhia Editora Nacional, 1933.

SAVIANI, Dermeval. História das ideias pedagógicas no Brasil. Campinas, São Paulo: Autores Associados, $2^{\mathrm{a}}$ ed., 2008. (Coleção Memória da Educação)

Escola e democracia: teoria da educação, curvatura da vara, onze teses sobre a educação política. Campinas, São Paulo: Autores Associados, 41 a ed., 2009. (Coleção Polêmicas de nosso tempo; 5)

Educação: do senso comum à consciência filosófica. São Paulo: Cortez/Autores Associados, 1985. Ensino, Pesquisa e organização na formação do campo da história da educação brasileira. In: MONARCA (org.); Nóvoa (prefácio). História da Educação Brasileira, Ijuí: Unijuí, 2005. (Coleção fronteiras da Educação)

em $01 / 12 / 2011$.

Autobiografia. Disponível em http://www.fae.unicamp.br/dermeval. Acesso

SAVIANI, D. História das ideias pedagógicas no Brasil. Campinas: Autores Associados, 2007. Resenha de: ALVES, G. L. Revista brasileira de Educação, v. 13, n. 37, p. 173-178, jan./abr. 2008.

História das ideias pedagógicas no Brasil. Campinas: Autores Associados, 2007. Resenha de: GONÇALVES, M. D. S. Cadernos de Pesquisa, v.39, n. 136, p. 320323, jan./abr. 2009.

VIDAL, Diana Gonçalves (org.). Dermeval Saviani: pesquisador, professor e Educador. Belo Horizonte: Autêntica/Autores Associados, 2001. (Coleção Perfis da Educação; 3)

VIEIRA, Carlos Eduardo. Cultura e formação humana no pensamento de Antonio Gramsci. Educ. Pesqui. [online]. 1999, vol.25, n.1, pp. 51-66. ISSN 1517-9702.

Notas

\footnotetext{
${ }^{1}$ Marc Bloch (2001) em sua obra Apologia da história ou o ofício do historiador aponta proposições para o ofício do historiador.

${ }^{2}$ A referida autobiografia está disponível no site www2.fae.unicamp.br/dermeval/auto.html\#0.
} 


\footnotetext{
${ }^{3}$ Saviani relata em sua autobiografia (p. 01): "Além de alguns fatos pitorescos, ficaram gravadas as doenças de infância, o desespero de minha mãe diante da ameaça de mortalidade infantil (ela perdeu a primeira filha e também aquele que seria o quinto) e a situação de penúria (lembro-me que saíamos à margem da estrada de ferro catando serralha para compor a alimentação familiar)".
}

${ }^{4} \mathrm{O}$ autor relata em sua autobiografia (p. 02) que em outubro de 1948, as dificuldades da vida da roça impossibilitavam a sobrevivência de uma família composta de casal e sete filhos (o oitavo nasceria depois, já em São Paulo) forçaram seu pai a se transferir com a família para a capital, São Paulo, onde se empregou como foguista de caldeira na indústria. E que o mesmo caminho seria seguido pela maioria de seus irmãos que também se tornaram operários na fábrica da capital. (p. 02)

${ }^{5} \mathrm{O}$ autor relata em sua autobiografia (p. 02): nessa instituição eram emitidos boletins mensais com as notas dos alunos e respectivas classificações. Revelei-me, no decorrer de todo o curso, um aluno dedicado e aplicado; em conseqüência, a cada mês, sem exceção, eu era invariavelmente classificado em primeiro lugar. Apenas uma vez, em 1958. Na $3^{\mathrm{a}}$ série, um colega empatou comigo em $1^{\circ}$ lugar com a média 8,8. Quando fui mostrar, como fazia todos os meses, o boletim ao padre com quem havia ido de São Paulo para Mato Grosso, ele me olhou com o semblante grave e disse: "você está relaxando e ficando displicente; o João Bosco já está te alcançando". E apontou com o dedo a primeira nota e escorregando-o para a média geral, falou: "no próximo mês quero ver esta nota $(9,5)$ aqui (na média final)". Retirei-me sem nada dizer. O mês seguinte era junho, mês dos exames semestrais. Prestei exame nas onze disciplinas do currículo e, recebido o boletim, levei-o até o mencionado padre que o olhou, conferiu na média final a nota 9,8, me devolveu, virou as costas e se retirou sem dizer uma palavra.

${ }^{6}$ Saviani narra que diferentemente do Seminário Menor onde predominava a rotina monótona e cujo conteúdo religioso se assentava numa espiritualidade mecânica, repetitiva e superficial, em aparecida vivia-se um clima de efervescência e que foi tomado de um clima de urgência. Sentiu que precisava queimar etapas e se situar rapidamente no quadro daquele clima. Acima de tudo era necessário definir os rumos de sua vida. As circunstâncias o haviam conduzido ao Seminário, mas ele entendia que a decisão de prosseguir nessa direção deveria decorrer de uma opção própria, lúcida, consciente e plenamente assumida, decorrente de uma motivação positiva e não apenas negativa. Vez por outra o assaltavam dúvidas radicais, existenciais. Então, decidiu deixar o Seminário. (Saviani, 2011, p. 05)

${ }^{7}$ Em 1994 a Biblioteca da Faculdade de Educação da Unicamprecebeu o nome do "Prof. Joel Martins", em uma homenagem aos múltiplos serviços que o emérito intelectual prestou ao desenvolvimento da Faculdade.

${ }^{8}$ Saviani $(2011$, p. 43$)$ relata que a idéia foi contestar as crenças que acabaram por tomar conta das cabeças dos educadores. Se o senso comum dominante entre os professores tendia a considerar a pedagogia nova como portadora de todas as virtudes e de nenhum vício e a pedagogia tradicional como portadora de todos os vícios e nenhuma virtude, buscou demonstrar exatamente o contrário, enunciando três teses polêmicas. Estas, na verdade, mais do que teses, funcionaram como antíteses por referência à concepção dominante e se traduziu na metáfora "teoria da curvatura da vara", isto é: se a vara está torta, para endireitá-la não basta colocá-la na posição correta; é necessário curvá-la do lado oposto. Assim, no debate das ideias, não bastaria enunciar a concepção correta para que os desvios sejam corrigidos; é necessário abalar as certezas, desautorizar o senso comum. Daí a estratégia de demonstrar a falsidade daquilo que é tido como obviamente verdadeiro, demonstrando, ao mesmo tempo, a verdade daquilo que é tido como falso.

${ }^{9}$ Para maiores informações consultar a obra de Saviani "Pedagogia histórico-crítica". São Paulo: Cortez / Autores Associados, 1991.

${ }^{10}$ Informações contidas na Cronologia da obra Dermeval Saviani: pesquisador, professor e educador, p. 11.

${ }^{11}$ Saviani escreve: Para Maria Aparecida, história de amor eterno, porque infinito e sempre dura. Para Benjamim: Quem está com a juventude que cultiva os clássicos possui o porvir.

12 Saviani, 2011, p. xvii.

${ }^{13}$ O Prêmio Jabuti é uma das maiores comendas brasileiras, iniciativa da Câmara Brasileira do Livro.

${ }^{14}$ Afrânio Peixoto em sua obra "Noções de História da Educação" de 1933 inicia cada capítulo com o item sincronismo, onde pretende nos situar no tempo e no espaço em relação ao contexto do tema abordado.

${ }^{15}$ Saviani, 2011, p. xviii. 
${ }^{16}$ Na primeira edição havia 351 referências bibliográficas, entretanto na $2^{\mathrm{a}}$ edição ele acrescenta mais três.
${ }^{17}$ Saviani (2011, p. 6) afirma que no contexto da chamada "nova história", a história das ideias é
provavelmente o "território historiográfico" mais abalado, tendendo a ser substituído pela história das
mentalidades ou história intelectual ou história cultural, aparecendo também expressões como história social
das ideias ou história sociocultural.

${ }^{18}$ Para Saviani (2011, p. 9) a terminologia (o tempo curto dos acontecimentos, o tempo médio das conjunturas e o tempo longo das estruturas), apesar de sua fecundidade, revela-se ainda presa aos limites formalistas próprios de uma lógica um tanto determinista que caracteriza o estruturalismo.

${ }^{19}$ Saviani (2011, p. 9) afirma que parece mais feliz a abordagem de Gramsci, que expressa, já na terminologia (movimentos orgânicos e conjunturais), o empenho em captar o processo em sua unidade dinâmica e contraditória.

${ }^{20}$ No Moderno Dicionário Enciclopédico Brasileiro (1986) “cardinalício" é um adjetivo concernente a cardeal e "cardinalista" é um substantivo que denomina o familiar de um cardeal. (p. 160). No mesmo sentido no Minidicionário Luft (2000, p. 147) "cardinalício" é um adjetivo relativo a cardeal (prelado).

${ }^{21}$ A palavra "cardinal" é um adjetivo de dois gêneros que pode significar principal, fundamental. (Luft, p. 147).

${ }^{22}$ Bontempi Jr afirma que "além das motivações imediatas, também deve ser objeto de análise a mecânica que movimenta e funcionaliza a história no campo da educação, uma operação que se dá por sedimentação de interpretações sobre um terreno crescentemente consensual de fatos históricos e problemáticas educacionais". (1999, p. 97)

${ }^{23}$ Para Ghiraldelli os problemas da obra "não tiram o mérito do livro de Saviani - é claro. O livro era necessário".

Recebido: $\quad$ março/13 Aprovado: setembro/13 